\title{
El Prontuario Numismático Antiguo Español (1849) de José de Viú. Notas para la historiografía numismática española del siglo XIX
}

\author{
Noé CONEJO DELGADO \\ Universidad de Sevilla. Departamento de Prehistoria y Arqueología \\ ccvdenoe@hotmail.com
}

Recibido: Enero 2015

Aceptado: Abril 2015

Resumen: En este artículo se realiza una crítica constructiva a una obra inédita sobre numismática de José de Viú. Por medio de su contextualización, llevamos a cabo la conexión del discurso expositivo de nuestro autor con otros coetáneos. Así pretendemos aportar una lectura nueva al desarrollo de la numismática antigua española en el siglo XIX:

Palabras clave: Erudición; Historiografía; Localismo; Numismática; Regeneracionismo.

The Compendium of Spanish Numismatic Ancient (1849) by José de Viú. Notes for Spanish numismatic historiography on XIX century

Abstract: In this paper, we make a constructive criticism about one unpublished numismatics book of José de Viú. We will provide a context for this book, and we will connect its contents with other contemporary authors. With this work, we hope to contribute one new reading about the development of Spanish numismatic ancient in the XIX century.

Keywords: Erudition; Historiography; Localism; Numismatics; Regeneration.

\section{INTRODUCCIÓN}

En el transcurso de una investigación particular localizamos en el Archivo Histórico Provincial de Cáceres un pequeño manuscrito firmado por José de Viú y contenido en el Legado Vicente Paredes Guillén. Tras una primera lectura y una posterior evaluación, se observó que su contenido y trayectoria eran suficientemente aptos para realizar un trabajo monográfico sobre el mismo. Este artículo es un resumen de un trabajo mayor que esperemos con suerte vea la luz en los próximos meses.

Así, en este presente, llevamos a cabo la presentación del manuscrito de Viú con una breve crítica constructiva, acompañada de unas notas biobibliográficas del 
autor, que nos permitirán contextualizar su obra y poder conectarla con otros autores coetáneos y con temáticas similares.

José de Viú es uno de los máximos exponentes del regeneracionismo extremeño, su influencia ideológica queda también plasmada en un trabajo sobre numismática, temática principal del manuscrito inédito. Este hecho ha sido observada en otros autores similares, quienes utilizan la moneda de manera indirecta para establecer un mismo discurso de regeneración o de conexión entre un presente y un pasado pretérito. Por ello, el recorrido bibliográfico y documental que hemos realizado, nos permite establecer otra perspectiva más para conocer el desarrollo del conocimiento de la numismática antigua en la España del siglo XIX.

\section{JOSÉ DE VIÚ: EL HOMBRE DE LAS LÁPIDAS}

Realizar una biografía completa de José de Viú sería un proyecto muy amplio que está siendo ahora mismo tratado por varios autores (Romero, 1986; 2012; 2013; Martínez Embrid, 2013), sin embargo, ha sido de vital importancia, tanto para nosotros como para los demás autores, las notas biográficas que el historiador Elías Diéguez Luengo aportó en los V Coloquios Históricos de Extremadura celebrados en Trujillo en 1977. La importancia de este breve trabajo, aún por editar, radica en dos aspectos fundamentales. En primer lugar por basarse en la autobiografía de José de Viú, conservada en la actualidad en el Archivo Privado de la Familia Peñaranda de Valencia de Alcántara (Cáceres). En segundo, por haber aportado un eje cronológico bastante acotado de la vida del autor, permitiéndonos entender con mayor claridad el significado de su obra epigráfica, pseudoarqueológica y regeneracionista extremeña.

José de Viú nace el cinco de junio de 1795 en el pueblo de Torla, de la provincia de Huesca, donde residirá hasta que en 1813, con 18 años, sea alistado en el Regimiento de Caballería de Cazadores de Navarra para asistir a los últimos momentos de la Guerra de la Independencia Española. Concluida la guerra, se gradúa de Bachiller de Leyes en la Universidad de Huesca, obteniendo una beca por oposición para seguir estudiando en el Colegio Imperial Mayor de Santiago en la misma ciudad. Así, en 1816 se gradúa de Licenciado y de Doctor en Leyes en Huesca. Durante unos años ejerce de abogado en la ciudad oscense y consigue la cátedra de derecho romano en el mismo Colegio donde estudió, aunque acaba estableciéndose como abogado en la ciudad de Jaca en 1818. Dos años después es nombrado por Fernando VII Juez de Primera Instancia en Cáceres, aunque había sido designado primeramente Fiscal de la Audiencia de Canarias, cargo que no llega a ejecutar por las complicaciones políticas del momento, según explica el propio Diéguez en palabras de Viú.

Después del Trienio Liberal, abandona Cáceres y reside en la vecina localidad de Alcántara durante toda la Década Ominosa al haber contraído matrimonio con su esposa en ese mismo lugar, de donde era natural. Este periodo de diez años será 
fundamental en su vida ya que será cuando producirá gran parte de su obra, la cual irá publicándose paulatinamente años siguientes. Entre ellas cabe destacar El Olimpo, una composición en la que se descifra la mitología grecorromana y la interpreta en armonía con el cristianismo (Viú, 1842: 107). Obra que se encuentra hoy inédita y que solo conocemos gracias a las notas que el autor realiza en sus trabajos posteriores sí publicados. De esta misma fecha también debemos citar a $E l$ Pirineo, que según Viú (1842: 107) "se aborda una descripción física y sentimental de esta cordillera por ambas vertientes.” Este trabajo, al igual que El Olimpo, no llega a publicarse, aunque recientemente ha sido comentado por Alberto Martínez Embid (2013) quien también realiza una revisión sobre el pensamiento regeneracionista de Viú y ahonda en cuestiones biográficas, las cuales nos han servido para completar las breves notas aportadas por Diéguez Luengo y las extraídas de la documentación conservada en el Archivo Histórico Nacional.

En 1833, José de Viú es nombrado por Fernando VII Alcalde Mayor de Valencia de Alcantara ejerciendo como Juez de Primera Instancia, y en 1834 recibe el título de Alcalde Mayor del Crimen de la Real Audiencia de Extremadura, resolución que le viene dada por la Reina Regente María Cristina de Borbón ${ }^{1}$. A partir de estas fechas seguirá trabajando en su producción intelectual rechazando varios nombramientos como Diputado a Cortes por Huesca en 1839 y Magistrado para Oviedo en 1845, debido principalmente a su delicada salud. Finalmente, Viú muere en Valencia de Alcantara el 19 de mayo de 1857 con 62 años.

Las dos últimas décadas de su vida son cruciales, ya que Viú realiza en este periodo de tiempo no solo la producción del trabajo por el que es conocido, sino que también durante estos años llevó a cabo una amplia recopilación documental como bien expone Diéguez Luengo. Pero esta recopilación debe entenderse desde dos perspectivas, las cuales condicionarán su pensamiento. Por una parte la recolección de todo tipo de noticias de hallazgos epigráficos, base de la redacción de su obra culmen: Colección de Inscripciones y Antigüedades de Estremadura [sic], publicada en Cáceres en 1846. Por otra parte, la creación de un inmenso archivo documental que solo conocemos gracias a los apuntes de Diéguez. No sería baladí que por estas mismas fechas empezara a forjar su colección numismática, de la cual solo tenemos constancia por varias notas en el trabajo que acabamos de referir y por un documento transcrito por Diéguez donde se expone que años después de la muerte de Viú su colección de monedas fue vendida por su hijo a un anticuario de Barcelona en 1864.

${ }^{1}$ Archivo Histórico Nacional. Signatura: Consejos. Legajo $n^{\circ}$ 13368. Expediente $n^{0} 153$ : Relación de los méritos, títulos, grados y ejercicios literarios del doctor Don José de Viú ex colegial imperial y mayor de Santiago de la Universidad y ciudad de Huesca y abogado de los Reales Consejos. Fecha 16 de noviembre de 1825; Signatura: Consejos. Legajo $n^{\circ} 13368$. Expediente $n^{\circ}$ 153bis: mismo título pero con fecha de 16 de diciembre de 1832; Signatura: Consejos. Legajo no 13368. Expediente $n^{\circ} 153$ ter: mismo título pero con fecha del 20 de junio de 1834. 
Pero Viú también es autor de otros trabajos que también fueron publicados, como las Aventuras de una Peseta, impreso en Cáceres en 1842 y las Medallas Parlantes, que vio la luz en Madrid en 1847. Ambos trabajos, que a pesar de sus respetivos títulos son lejanos a la temática numismática, consisten en una historia de España desde un punto de vista subjetivo, contada en tercera persona, como si fueran las propias monedas quien escribieran el propio relato. Su disposición y forma recuerda bastante al género epistolar de José Cadalso. Pero sin duda, la obra clave de su trayectoria fue la citada Colección de Inscripciones y Antigüedades de Estremadura [sic](1846) y la reedición de esta en Madrid titulada Estremadura [sic] Colección de sus inscripciones y monumentos seguida de reflexiones importantes sobre lo pasado, lo presente y el porvenir de estas provincias (1852). La ardua tarea de reunir un gran número de noticias histórico - arqueológicas y una multitud de datos epigráficos repartidos por Extremadura para su redacción, le valió a Diéguez como perfecto argumento para otorgar a Viú el sobre nombre de "El Hombre de las Lápidas”.

Viú ha pasado a la historia de Extremadura como un gran erudito, y de hecho autores como Ortíz Romero (2013: 119) lo han catalogado como el protoarqueológo extremeño, por intentar llevar a cabo la redacción de una historia extremeña con una base arqueológica, datos epigráficos y noticas recibidas de varios amigos - informantes repartidos por la región. Pero a pesar de ello, su verdadero propósito era el de encontrar en la Antigüedad la vía principal para buscar la regeneración de Extremadura (Ortíz, 2012), que será el principal cometido de la reedición de 1852, donde definitivamente la arqueología acaba siendo relegada a un segundo o tercer término a favor de un pensamiento regeneracionista difundido de manera propagandística, donde los extremeños deberían apostar por el progreso y por un futuro mejor, apoyándose en lo que fueron en siglos pasados.

En esta tesitura nace el Prontuario Numismático Antiguo Español, una tercera parte de la reedición de 1852 que nunca llega a publicarse y que abordaremos en el siguiente punto con más detenimiento.

\section{COMENTARIO CRÍTICO AL PRONTUARIO NUMISMÁTICO ANTIGUO ESPAÑOL (1849)}

\subsection{TRAYECTORIA DEL DOCUMENTO}

Recorrer toda la historia del Prontuario Numismático Antiguo Español daría para un solo artículo, por otra parte, toda su problemática quedó bien explicada por Pablo Ortiz Romero cuando analizó las relaciones entre José de Viú y la Comisión de Monumentos de Badajoz (Ortiz, 2013). No obstante, llevaremos a cabo un breve recorrido por toda su trayectoria, pues es necesario para conocer por qué esta obra ha permanecido inédita hasta nuestros días. 
Viú expresa en las primeras páginas de este manuscrito la necesidad de escribir un pequeño manual de iniciación a las ciencias numismáticas para principiantes. En su obra de 1846, había recogido en la parte final una serie de índices que enumeraban todos los pueblos y municipios que según él habían acuñado moneda en la Península Ibérica, y que son la antesala del citado manuscrito, pues bien queda referido cuando afirma a modo de nota al pié que los detalles y explicaciones de estas monedas se agrupan en un Manual Numismático Antiguo Español que se encuentra inédito.

Este manual estaba concebido como una parte complementaria de la reedición de 1852 (Ortiz, 2013: 138 - 140) pero que finalmente, por decisión del propio Viú será apartada de dicho proyecto por no encontrarse, según él, relacionada la numismática con la temática principal de la reedición. Esta decisión estuvo condicionada por la buena consideración que Viú tenía de su propio trabajo, quien alentado por la necesidad y practicidad de este, no se le impediría publicar el Prontuario en un breve periodo de tiempo. Movido por esas buenas apreciaciones, Viú decide remitir el Prontuario a la Real Academia de la Historia con la intención de que esta Institución lo publique. La Academia, a su vez, envía el trabajo de Viú al conservador del Gabinete de Antigüedades, Antonio Delgado Hernandez por estos momentos, para que realizara un informe de evaluación sobre dicho trabajo y así, sopesar la posibilidad de publicación o no.

El informe de Delgado ${ }^{2}$ no se hizo esperar y su veredicto fue bastante claro, pues la obra de Viú carecía de los fundamentos metodológicos y bibliográficos necesarios para un trabajo entendido como manual de consulta. Por otra parte, Delgado no solo se limita a realizar una dura crítica, sino que también expone un breve estado de la cuestión sobre la situación de los estudios numismáticos españoles a comparación con los europeos coetáneos, demostrando así el evidente retraso de las obras españolas en cuestiones de tipo técnico y metodológico.

Por tanto, estamos ante un intento de manual de consulta con unas carencias metodológicas y bibliográficas evidentes, pero que presenta cierto interés desde un punto de vista historiográfico.

Al ser rechazada la propuesta de publicación, la Real Academia de la Historia reenvía el manuscrito a Viú y es así cuando se le pierde la pista durante bastantes años. A principios del siglo XX, el erudito plasencino Vicente Paredes Guillén lo adquirirá y

\footnotetext{
${ }^{2}$ Archivo de la Real Academia de la Historia. Signatura: GN 1854/5(1): Informe sobre el Prontuario Numismático Antiguo Español de José de Viú, por Antonio Delgado y Hernández. Madrid. 22/12/1854. Puede ser consultado online en el siguiente enlace: http://www.cervantesvirtual.com/obra-visor/informe-sobre-el-prontuario-numismatico-antiguoespaol-de-jose-de-viu-en-el-que-realiza-un-estado-de-la-cuestion-de-los-estudiosnumismaticos-en-europa-y-de-la-escasez-de-ellos-en-espaa-con-referencia-de-losinvestigadores-sus-obras-y-sus-avances/html/ [consultada día 16 de marzo de 2015]
} 
a su muerte, lo donará junto a todo su legado al Archivo Histórico Provincial de Cáceres donde se encuentra hoy custodiado dentro de ese mismo legado ${ }^{3}$.

\subsection{ESTRUCTURA DEL PRONTUARIO}

El Prontuario Numismático Antiguo Español se divide en varias partes: una nota preliminar, cuatro amplias secciones y cuatro apéndices, de los cuales, los dos primeros ya se habían publicado en la obra de 1846. Por lo que respecta a las secciones, carecemos de la segunda, pues el manuscrito nos ha llegado incompleto. Para un mejor entendimiento, iremos explicando cada parte por separado.

La Advertencia y Preliminar abren este Prontuario a modo de introducción. En unas cuantas páginas, nuestro autor establece los motivos que le han llevado a la creación de este, que como ya hemos podido comprobar en líneas anteriores es la redacción de un manual de apoyo para estudiantes. Pero también se pueden extraer de estas primeras páginas lo que parecen unas notas sobre la metodología que decide adoptar en el trabajo. Descripción subjetiva de los tamaños de las monedas, algunas aclaraciones sobre la denominación de las piezas o la variedad iconográfica de tipos monetales, son los aspectos que más se pueden acercar a una metodología típica de un manual de numismática, pero como el propio Antonio Delgado Hernández estableció en el citado informe, existían ya por Europa y España una serie de criterios mucho más técnicos y serios muy alejados de los adoptados por Viú, y que como hemos podido comprobar, poco cercanos a la objetividad. A esta falta de criterio hay que añadir una compleja disposición explicativa llevar a contradecir al propio Viú, demostrando así que nuestro autor empezó la obra sin haber definido previamente un orden de ideas.

Por lo que se refiere a la Primera Sección, titulada Colonias Españolas que acuñaron con expresión de tipos, realiza la descripción de 15 cecas (Acci, Asta Regia, Cesar Augusta, Cartago Nova, Celsa, Carteia, Clunia, Corduba, Detosa, Emerita Augusta, Hispali, Ilici, Itvcci, Tarraco y Valentia). La Segunda Sección, cuyo contenido se encuentra perdido hoy, estaba titulada como Municipios que acuñaron moneda y hubiese comprendido la explicación de 29 cecas (Alpesa, Arva, Anticaria, Bellia, Calaguirris Fibularia, Bilbilis, Calagurris Nasica, Carmo, cascatum, Castulón, Celti, Eporiae, Ercavica, Gades, Gracurris, Hibera Julia, Ilerda, Ilipa Magna, Italida, Monda, Obulco, Osca, Ossicerda, Osset, Saetabi, Saguntum, Siarum, Turiaso, Ulia). Conocemos las cecas que fueron descritas gracias a uno de los índices de la obra de 1846 (Viú, 1846: 280 - 284). La

${ }^{3}$ Archivo Histórico Provincial de Cáceres. Legado Paredes Guillén. Caja no ${ }^{\circ 4}$. Expediente $\mathrm{n}^{\circ}$ 9. Se conserva el manuscrito Prontuario Numismático Antiguo Español incompleto y una carta emitida por la Real Academia de la Historia, firmada por Pedro Sabau, Secretario de la Academia, el 23 de diciembre de 1854, donde se exponía el motivo de la devolución de una manera muy sutil : "no ser posible a la Academia hacerlo imprimir por cuenta suya”. 
Tercera Sección recibe el título de Pueblos que sin ser colonia ni municipios acuñaron por privilegio o por tolerancia, aquí se lleva a cabo el estudio de un total de 29 cecas (Abdera, Acinipo, Aria, Bellón, Carisa Aurelia, Callet, Carbula, Caura, Ceret, Ebora, Julia Traducta, Ilurcan, Ipargo, Iripo, Laelia, Lastigi, Lontigi, Luciferi Fanum, Onuba, Urci, Orippo, stipo, Ostur, Salici, Segovia, Segobriga, Spoletum, Toletum y Ventipo). Por último, la Cuarta Sección recibe el nombre de Sobre las medallas anteriores a los romanos en España y letras llamadas desconocidas. Aquí Viú reflexiona sobre la existencia de varios alfabetos prerromanos y realiza la explicación de algunas monedas no citadas en las cecas anteriores para ser ejemplo de sus discursos. De todas formas, su recorrido por los diferentes alfabetos es un parafraseo de los trabajos de Velázquez (1752) y de Pérez Bayer (1772), junto a un particular punto de vista.

Por lo que respecta a los apéndices, como ya hemos expuesto, los dos primeros están publicados en su obra de 1846, de hecho ni si quiera los desarrolla, limitándose a hacer un llamamiento al lugar donde se encuentran en la publicación citada. Los otros dos sí son explicados por Viú en el manuscrito. El tercero, que recibe el nombre de Breve reseña sobre la población antigua de España y el cuarto, Sobre la riqueza de España. Estos apéndices son una serie de reflexiones que según nuestro autor complementan las descripciones y explicaciones que realiza de los tipos en las secciones anteriores. Podemos adelantar que el contenido de estos apéndices no tiene nada que ver con la temática numismática, y aunque la aluden, esta quedará siempre en un plano totalmente secundario o terciario, por tanto, en la misma posición en la que queda la Arqueología en su reedición de 1852.

\subsection{CONTENIDO Y CRÍTICA}

Ir revisando ceca por ceca generaría un trabajo demasiado extenso, por ello, a favor de la síntesis hemos preferido extraer los elementos más significativos y, de paso, explicar cuáles fueron las fuentes de inspiración que hemos podido identificar. Como también se ha expuesto en la Introducción de este trabajo, las cecas serán comentadas en profundidad en un trabajo monográfico sobre el Prontuario que esperemos vea la luz en los próximos meses.

Como se puede comprobar en los listados que hemos ofrecido, José de Viú organiza las cecas con una serie de criterios propios basados en las lecturas de autores grecorromanos y en la tradición numismática española del momento. Este hecho también fue criticado por Delgado, quien para estas fechas ya abogaba por la diferenciación cronológica y geográfica, plasmada unos años después en su Nuevo Método de 1871 - 1876. Por ello, las descripciones tipológicas y las ubicaciones geográficas de las cecas que Viú describe estarán condicionadas por las lecturas de obras numismáticas españolas claves como la de Antonio Agustín (1587), Velázquez (1752), Florez (1757 - 1758), Pérez Bayer (1772), Gusseme (1773) o Valcárcel (1773), quienes también beben de las obras clásicas. Pero Viú 
no solo utilizó estos trabajos como base para el Prontuario, sino que también se valió de otros que intentaron recomponer la historia de España o de alguna de sus regiones valiéndose de los restos arqueológicos, epigráficos y numismáticos aparecidos hasta el momento. Estos trabajos en algunas ocasiones carecen de cierto rigor, pues asimilan planteamientos sin fundamento a los citados restos, generando ideas erróneas que fueron adoptadas por el propio Viú, quien no se preocupó de realizar un cotejo de la información que utilizaba. Entre las obras más destacadas de tipo que hemos podido identificar en el Prontuario citamos las Antigüedades de Rodrigo Caro (1634), la España Sagrada de Flórez, la Historia crítica de España y de la cultura Española de Masdeu (1785), el Sumario de Antigüedades Romanas de Cean Bermudez (1832) o el Diccionario geográfico histórico de la España Antigua de Cortés y Cortés (1836).

Ante la falta de criterio existente en el Prontuario debemos citar una carencia heurística y hermenéutica, pues Viú no aporta ninguna novedad al discurso numismático del momento, es más, tiende a generar más ruido debido a que acepta como verdaderos los planteamientos de algunos autores que carecen de formación numismática. Estos errores serán posteriormente solventados mayoritariamente por Heiss (1871) y por Delgado $(1871-1876)$.

Por tanto, ¿qué tiene de especial el Prontuario de Viú para la historiografía numismática española? En primer lugar no se puede considerar como una obra de referencia, pues como bien se ha podido comprobar, el manuscrito podría tomarse de ejemplo para explicar la intención de muchos eruditos locales de acercarse a temas tan específicos como la numismática, motivados principalmente por afición o coleccionismo. Debemos recordar que Viú poseyó una colección de monedas, pero en ningún momento afirma que sea esa su fuente de inspiración.

Lo más significativo del trabajo de Viú es la manera tan particular que tiene para dar una explicación acerca de los motivos iconográficos que se observan en las monedas de cada ceca, como son reflexiones sobre un pasado dorado de las cecas, las viejas glorias de los pueblos y municipios, sus inmensas riquezas naturales y materiales e incluso la capacidad de algunos pueblos, según él, de hacer frente al poder de Roma. Esta postura define el discurso de Viú en el Prontuario con un marcado carácter regeneracionista, pues en múltiples ocasiones nuestro autor establece conexiones entre el pasado y el presente a través de esas iconografías monetales. A su vez, esta idea se encuentra mucho más marcada en los respectivos apéndices donde reflexiona sobre las antiguas poblaciones que vivieron en la Península Ibérica, antes de la llegada del Imperio Romano y sobre las riquezas que estos poseían. En estas últimas páginas, Viú opina sobre el devenir de los pueblos y como estos acabaron generando los inicios de nuestra cultura al fundirse con los ideales romanos. Por su parte, a través de los datos ofrecidos por las fuentes grecorromanas, Viú cavila sobre esos tiempos pasados de gloria enrevesado su discurso de una manera muy 
compleja, alejándose por tanto de la propia numismática a favor de conceptos como el del expolio romano de las riquezas ibéricas.

Esta tendencia que hemos advertido, nos lleva a pensar en que Viú utilizó el Prontuario como un elemento de ensayo para su reedición de 1852, al encontrarse así los inicios de su marcado regeneracionismo posterior pero ya advertido en la obra de 1846. Por otra parte, la decisión de no incluir este Prontuario en la reedición no fue exclusivamente por disparidad de temas, pues al fin y al cabo, en ambas partes pretenderá difundir un pensamiento regeneracionista, pero mientras la reedición de 1852 tendrá como principal objeto de reflexión la regeneración de Extremadura, en el Prontuario se recopila tipos monetarios junto a glorias pasadas, donde el discurso regeneracionista se encuentra presente pero de una manera soterrada.

Desde un punto de vista numismático la obra carece de interés por las razones que ya hemos expuesto, pero desde un punto de vista historiográfico sí debe tenerse en cuenta, ya que la manera que Viú adopta para reflexionar sobre la moneda como elemento intrínseco para conocer momentos pretéritos y su capacidad para conectarlas con su contemporaneidad, es la verdadera esencia del Prontuario. Salvando el pensamiento regeneracionista, esta misma estrategia de conexión de tiempos ha sido advertida en otros autores coetáneos, permitiéndonos establecer vínculos entre ellos mismos y Viú, como se expondrá en el siguiente punto.

\section{CONTEXTUALIZACIÓN DE LA OBRA NUMISMÁTICA DE JOSÉ DE VIÚ Y OTROS TRABAJOS COETÁNEOS}

Conocer las producciones numismáticas coetáneas al momento de la redacción del Prontuario no nos ha sido complicado, ya que ha sido de vital importancia para ello el Informe de Antonio Delgado que hemos citado anteriormente. Delgado, afirma con resignación que desde tiempos de Flórez, Velázquez o Pérez Bayer no se ha publicado en España ninguna obra numismática de referencia, cuando en Europa ya la numismática había traspasado la consideración de erudición a favor de una ciencia moderna, gracias sobre todo a un gran número de especialistas creadores de una serie de metodologías que siguen vigentes hasta hoy, como la agrupación de cecas en función de áreas geográficas y la evolución cronológica.

En cierta medida la obra de Viú podía haber roto con esta norma si verdaderamente hubiese alcanzado la calidad metodológica y bibliográfica necesaria como para ser un manual de consulta. De todas maneras, a principios del siglo XIX ya existían algunos trabajos dignos de romper con dicha escasez de producciones. Nos referimos por ejemplo a los manuscritos de Guillermo Pérez 
Bustamante $^{4}$ y de Dámaso Puertas, conservados en la Biblioteca de la Iglesia de Giacomo degli Spagnoli de Roma. Ambos autores trataron de una manera muy interesante y adelantada a su tiempo los caracteres celtibéricos de la moneda hispánica, siendo copiados tales ideales por otros autores como Sestini, según Mora (1995) que fue quien los dio a conocer.

A su vez, esta documentación inédita convive con multitud de escritos, ensayos y disertaciones conservadas en los archivos y bibliotecas de muchas instituciones españolas. Documentos que demuestran la existencia de una serie de conocimientos numismáticos basados en estas metodologías europeas advertidas por Delgado. Los ejemplos más significativos de este tipo de documentación son los informes e inventarios que los Anticuarios de la Real Academia de la Historia hacían sobre su Gabinete Numario. Aquí se puede comprobar perfectamente una evolución marcada por estas influencias extranjeras. Este hecho manifiesta que, el no existir obras de referencia publicadas como expuso Delgado, no quiere decir que no existieran tales conocimientos.

Por otra parte, no hemos encontrado ningún manuscrito con características similares a la obra de Viú, es decir, un manual de consulta. Quizás el documento inédito que más pudiera habérsele parecido sea el libro que José Antonio Enriquez tuvo intención de escribir y del cual solo nos ha llegado su índice titulado como Introducción a la ciencia para entender las medallas y antiguas monedas especialmente de España y con particularidad de las ciudades de Cádiz(...) y que se encuentra conservado en el Archivo Histórico Nacional ${ }^{5}$, de todas formas se volverá a citar este autor en las siguientes líneas. Similar pero con otros tintes destacamos un manuscrito conservado en la Biblioteca Nacional, firmado con las siglas A.M. en 1802, y que recibe el título de Estudio de las monedas antiguas y modernas que han corrido en España aplicado a su Historia y Legislación ${ }^{6}$. Con un desarrollo de tipo epistolar, este amplio trabajo reflexiona bastante sobre la moneda castellana de época medieval aportando un gran número referencias legislativas. Por su parte, el tema de la moneda antigua española no es para nada loable, pero hemos decidido sacarlo a colación por tener cierto parecido con la obra de Viú, en cuanto estructura se refiere.

De todas formas, aunque el Prontuario fue escrito en ese periodo de tiempo que oscila entre las obras de Velázquez y Flórez hasta Delgado, existen un gran número de ejemplos que sin ser obras claves de la numismática antigua española, se conectan perfectamente con la postura regeneracionista que adoptó Viú para la

\footnotetext{
${ }^{4}$ De este mismo autor existen otros manuscritos en la Biblioteca Nacional de la misma temática. (Manuscrito $\mathrm{n}^{\circ}$ 8973).

${ }^{5}$ Archivo Histórico Nacional. Sección: Estado. Legajo $n^{\circ}$ 4822. Expediente 15. Introducción a la ciencia para entender las medallas y antiguas monedas especialmente de España y con particularidad de las ciudades de Cádiz(...)

${ }^{6}$ Biblioteca Nacional. Manuscrito no 13272.
} 
redacción de su manual numismático. Nos referimos por tanto, a todas esas historias locales y regionales que empiezan a surgir a principios del siglo XIX.

La utilización de los restos arqueológicos y la propia numismática como elementos principales para designar la antigüedad de las ciudades en España, es una práctica que ya había surgido en época renacentista y que para principios del siglo XIX seguía siendo una práctica recurrente, como seguirá siéndolo hasta la actualidad. Casos muy utilizados como referencia son el de Bernabé Moreno de Vargas con su Historia de la Ciudad de Mérida, publicado en 1633, o la ya citada por nosotros Antigüedades y principado de la Ilustrísima ciudad de Sevilla y corografía de su convento jurídico o antigua Chancillería de Rodrigo Caro (1634).

Este tipo de obras, y las siguientes, presenta una serie de características comunes: la utilización de la antigüedad como restos de arquitectura, inscripciones y monedas, como principal apoyo para ilustrar el esplendor de un pasado lejano y hacerlo llegar a nuestro presente. Por tanto, esta características no se encuentra muy lejana de las trazas regeneracionistas advertidas en la obra de José de Viú con las Antigüedades de Estremadura [sic] y el Prontuario, ya que tanto nuestro autor como los que a continuación comentaremos realizan una perfecta conexión entre un pasado pretérito e irrepetible y el momento presente.

A modo de ejemplo, citamos la Historia General de Córdoba de Francisco Ruano (1761), quien usa las monedas acuñadas por esta ciudad en época romana como signo de su importancia como capital de la provincia Bética. Actuación muy recurrente, y no tan llamativa, como la comparación que realiza Francisco Cascales (1776) con los tipos monetales de época romana y los elementos que componen los escudos nobiliarios de los diferentes linajes que existen en la ciudad de Murcia.

Significativa resulta la obra de Fray Pascual de Salmerón con su La antigua Carteia, ó Carcesa, hoy Cieza (1777), y complementaria con la Dissertación numismática y laberíntica sobre una medalla de Carteia (1784). Salmerón lleva a cabo una reflexión bastante interesante, a la par que errónea para establecer que las monedas acuñadas en Carteia (San Roque, Cádiz) no pertenecen a tal yacimiento arqueológico, sino a la antigua ciudad de Cartei, que se encontraba en la actual Cieza, Murcia, como así establecerá en el Capítulo VII de esta última obra que hemos señalado. Sus reflexiones son apoyadas en las interpretaciones que realiza de los trabajos de autores como Flórez y Valcárcel, pero con ciertas carencias de fiabilidad, pues al fin y al cabo, Salmerón pretendía demostrar lo genuina que podía resultar la historia de Cieza. Respecto a las demás aportaciones numismáticas de su obra, no son de mucha novedad, pues se limita a ir revisando los trabajos de los autores anteriores.

Años después a la obra de Salmerón, quedó escrita una propuesta de obra que nunca llegó a ser concluida. Su autor, Juan Antonio Enriquez Lozano, ya citado en líneas anteriores, era natural de Cádiz y ocupó importantes cargos como Comisario 
de Guerra, miembro del Consejo de Guerra y su secretario con ejercicio de decretos ${ }^{7}$. En el expediente que se conserva en el Archivo Histórico Nacional sobre este autor, encontramos un gran número de escritos suyos basados fundamentalmente en la historia de su ciudad natal. De hecho, recoge una noticia acerca de una moneda de oro aparecida en las obras del Canal de Castilla en dicha ciudad y que remite a la Real Academia de la Historia para su estudio ${ }^{8}$, por lo que se puede considerar un gran erudito conocedor de la historia local y de la historia en general, apoyándonos en el inventario que realiza de su propia biblioteca, conservado en su mismo expediente.

Pero lo más significativo de este autor es la intención de llevar a cabo la redacción de una obra recopilatoria sobre numismática antigua. Sabemos de dicha intención por encontrarse en uno de los documentos de dicho expediente, no solamente el título y una breve descripción, sino también una propuesta de índice que nos permite conocer el impacto que dicha obra hubiese generado en el caso de que hubiese sido publicada. Así, en el documento fechado el 7 de junio de 1803, vemos el desglose de una Introducción a la ciencia para entender de las medallas y antiguas monedas especialmente de España con particularidad de las ciudades de Cádiz, San Lucar de Barramenda desde el tiempo de los fenicios hasta los godos. Obra que presentará un total de 46 de capítulos, de los cuales varios serían dedicados a las monedas acuñadas por las dos ciudades que aparecen en el título. Llevando a cabo el análisis del respectivo índice, vemos que algunos de los títulos de capítulos recuerdan a obras europeas coetáneas, por tanto no sería descabellado pensar que nuestro autor realizara para ello resúmenes de los trabajos europeos más importantes, con los cuales introducir el tema a discutir.

Con el paso de los años, las obras de historia local se multiplicaron, sobre todo bien entrado el siglo XIX. Así, destacamos por ejemplo a autores como Agustin Horozco con su Historia de la Ciudad de Cádiz (1845), quien utiliza la moneda como elemento definitorio de la antigüedad de la ciudad; al contrario de la obra de Aldolfo de Castro Rossi con un título parecido al anterior y publicada en el mismo año. El autor prescinde de la numismática, siendo necesaria para conocer la historia de Cádiz. Por otra parte, destaca la obra conjunta de Albiña y de Borrás y

${ }^{7}$ Los datos que aportamos sobre Enríquez han sido extraídos del Archivo Histórico Nacional. Signatura: Estado Legajo 4822, expediente número 15. Aquí se han encontrado papeles impresos con una cabecera en la que se encuentran recogidos dichos datos: "Juan Antonio Enríquez, del consejo de su Majestad, su secretario, comisairo real de la Guerra de Marina, y ministro principal de ella de la provincia de Sevilla, juez privativo de la conservación de montes y plantios en los pueblos de su promprensión y de arribadas de vaxeles del Comercio de Indias”.

${ }^{8}$ Archivo Histórico Nacional: Signatura: Estado. Legajo 4822. Expediente 15. Carpetilla de Glorias marítimas de España. Hace referencia a una medalla de oro que se encuentra en Cádiz y que representa a Hércules y que se manda a la RAH. Pero no encuentran paralelo. 
Bofarull, titulada Tarraco Monumental (1849), donde se pueden apreciar afirmaciones como "con el fin de perpetuar la memoria de los acontecimientos notables (los habitantes de Tarraco) acuñaron moneda" (Albiña / Bofarull, 1849: 160), haciendo alusión a la grandeza de la capital tarraconense a través de los motivos iconográficos que pueden encontrarse en monedas acuñadas por esta ceca.

En esta misma línea hay que citar la obra de Miguel Lafuente Alcántara sobre la Historia de Granada (1852), quien también utiliza la numismática para caracterizar la historia de algunas ciudades antiguas como la de Acci, actual Guadix, o la de Iliberri, actual Granada.

Por lo que respecta a la obra de Soler y Arqués sobre la Historia de la ciudad de Huesca (1861), la numismática no únicamente se utiliza para demostrar la antigüedad de la ciudad romana de Osca, sino que también los documentos monetarios son empleados para argumentar lo particular que resultaron dichas monedas en la historia del Imperio Romano:

La moneda oscense es la que más abunda, como hemos dicho, en los museos de Europa. Sacada de los criaderos de los Pirineos, fabulándose en tanta abundancia que los cónsules y generales romanos la introducían a cargas en la capital del mundo, entre ovaciones y triunfos (Soler y Arqués, 1861: 47).

Un año más tarde, vio la luz la Historia de la ciudad de Toledo, publicada por Antonio Martín Gamero (1862), en quien también se puede apreciar una actitud parecida a la de Soler y Arqués, pero únicamente cuando se habla de moneda visigoda acuñada en la antigua Toletum.

Así, el recorrido que hemos efectuado por una selección de estas obras, pues seguramente existan más ejemplos, nos ha permitido establecer una serie de conclusiones que nos proporcionan una idea general de este fenómeno. En primer lugar, los autores que se han mencionado, presentaban dos características principales. Por una parte, son personas con gran formación en el mundo de las fuentes clásicas, y por tanto, cercanos a restos arqueológicos, bien de manera directa por ser coleccionistas, bien de manera indirecta, al recurrir a colecciones particulares de conocidos como base de sus argumentos. Por otra parte, estos eruditos presentaban un vinculo especial con la ciudad sobre la que escriben, pues generalmente es su ciudad natal o ciudad de adopción, donde van a permanecer hasta sus últimos días. Este hecho es fundamental, ya que les permite establecer buenas relaciones con otros eruditos, teniendo acceso a archivos y colecciones particulares, o valiéndose de datos que sus cercanos le ofrecían, muchas veces procedentes de falsas invenciones tradicionales con mucha antigüedad y admitidas como verdaderas al no haberse producido una refutación de tales ideas.

La utilización de la numismática en este tipo de trabajos es clave. La moneda era interpretada como un verdadero documento histórico que no ha sido adulterado 
en el tiempo. A este hecho se le debe sumar la facilidad con la que puede ser estudiada y también adquirida, pues, o bien son los autores quienes poseen las piezas, o bien se valen de gabinetes particulares para la redacción de sus obras. Pero dicha utilización permite a su vez generarnos dos lecturas: por una parte, los autores que emplearán la moneda como mero documento, sobre el cual apoyarán la antigüedad propuesta del lugar que estudian; por otra parte, autores que verán en la moneda un elemento genuino que aporta la suficiente particularidad a la historia de su localidad, como para establecer diferencias entre unas y otras, muchas veces con trazas de arrogancia, como hemos podido comprobar en los dos últimos autores que hemos señalado.

A modo de cierre de este punto, podríamos decir que José de Viú se va a incluir a caballo entre ambas tendencias, pero desde la propia epigrafía. Es cierto que en la edición de 1852 de sus Antigüedades de Estremadura [sic], la epigrafía será el pretexto para una obra dedicada a la regeneración de la propia Extremadura (Ortiz Romero, 2012), pero la primera edición, de 1846, sí que se basa principalmente en la epigrafía, con unas notas muy puntuales hacia la numismática para recorrer la propia región y ser el argumento perfecto con el cual demostrar el pasado glorioso del que gozó Extremadura. En el Prontuario, la situación cambia, pues aquí sí que utiliza la numismática como elemento particular, pero no de la entidad que acuña cada moneda, sino para manifestar lo genuina que resulta la adscripción crono - cultural que él propone para cada una de ellas. Viú demuestra ser el erudito local por excelencia, y en archivo particular señalado por Diéguez nos apoyamos para reconocerlo como tal. Su actitud de recopilación le permitió ganarse un hueco entre los eruditos extremeños, convirtiéndose, según Ortíz Romero (2012; 2013: 113 - 160), en una de las figuras claves para entender los primeros momentos de la arqueología extremeña sin haber llegado nunca a realizar una excavación arqueológica.

\section{CONSIDERACIONES FINALES}

Después de una valoración crítica de la obra inédita de José de Viú y la búsqueda de conexiones con otros autores coetáneos y de pensamientos muy parecidos, tan solo podemos afirmar que muchos años antes de que surgiera el pensamiento regeneracionista tal y como lo conocemos, ya existían autores que de una manera indirecta y quizás con total desconocimiento, estaban realizando discursos muy asimilables a esta corriente ideológica de finales del siglo XIX.

En cierta medida Antonio Delgado Hernández tenía razón al exponer en el Informe sobre el Prontuario de Viú la carencia de obras numismáticas en España por esas fechas, pero también tenemos que considerar que sí existían los conocimientos numismáticos necesarios para realizarlas. Por otra parte, ligar los datos numismáticos aportados por estos autores locales y regionales a planteamientos de tipo regeneracionista, nos debe aportar un nuevo punto de vista para conocer mejor el desarrollo de la numismática en el siglo XIX. Al fin y al 
cabo se vuelve a poner de manifiesto la presencia de esos conocimientos venidos de Europa, pero amoldados a las necesidades del momento: el surgimiento de historias nacionales, regionales y locales por el desarrollo de pensamientos de tipo nacionalista, regionalista y localista, también llegados del viejo continente.

Por ello, aunque la obra de Viú carece de importancia desde un punto de vista metodológico y bibliográfico, debe reconocerse por haber sido necesaria para poder conocer esta nueva perspectiva, que quizás con el tiempo sea mucho mejor conocida al permitirse nuevas lecturas y mejores conexiones entre sus contemporáneos.

\section{REFERENCIAS BIBLIOGRÁFICAS}

AGUSTÍN, Antonio (1744): Diálogos de medallas, inscripciones y otras antigüedades. Madrid: Joseph Fca. Martínez Abad.

ALBIÑA y DE BORRÁS, Juan Francisco y BOFARULL Y BROCÁ, Andrés (1849). Tarraco Monumental. Descripción histórica y artística de todas sus antigüedades y monumentos celtas y romanos. Tarragona: Aris i Junet

CARO, Rodrigo (1634). Antigüedades y principado de la Ilustrísima ciudad de Sevilla y corografía de su convento jurídico o antigua Chancillería. Sevilla: Impresor J. de Haro.

CASCALES, Francisco (1776). Discursos históricos de la muy noble, muy leal ciudad de Murcia. Murcia: Impresor Francisco Benedito.

CASTRO Y ROSSI, Adolfo de (1845). Historia de la muy noble, muy leal y muy heroica ciudad de Cádiz. Cádiz: [s.n.].

CEAN BERMUDEZ, Juan Agustín (1832). Sumario de las antigüedades romanas que hay en España. Madrid: Biblioteca valenciana.

CORTES Y LÓPEZ, Miguel (1836). Diccionario geográfico - histórico de la España antigua.

DIÉGUEZ LUENGO, Diego (1977). “José de Viú. El hombre de las Lápidas”. V Coloquios Históricos de Extremadura. Trujillo.

FLOREZ, Enrique (1757). Medallas de las colonias, municipios y pueblos antiguos de España. Madrid: Impresora Antonio Marín.

GUSSEME, Tomás (1773). Diccionario numismático general para la perfecta inteligencia de las medallas antiguas, sus signos, notas $e$ inscripciones $y$ generalmente todo lo que se contiene en ellas. Madrid: Impresor Joaquín Ibarra.

HERNÁNDEZ DEL PORTILLO, Alonso (1994). Historia de la muy noble y más leal ciudad de Gibraltar. Algeciras: Centro asociado de la UNED.

HEISS, Aloiss (1871). Description génerale des monnaies antiques de l'Espagne. Paris: E. Leroux.

HOROZCO, Antonio (1845). Historia de la ciudad de Cádiz. Cádiz: Impresor Manuel Bosch. 
LAFUENTE ALCANTARA, Manuel (1852). Historia de Granada. Compendio de las cuatro provincias Almería, Jaén, Granada y Málaga desde tiempos remotos hasta nuestros días. Granada: Impredisur.

MORALES, Ambrosio de (1575). Las Antigüedades de las ciudades de España. Alcalá de Henares: Impresor Iñiguez de Lequerica.

MARTÍNEZ EMBID, A. (2012). "Los Pirineos según el doctor José de Viú. Notas sobre un manuscrito de 1832 desconocido en tierras aragonesas", en Temas de antropología aragonesas. $\mathrm{N}^{\circ} 19 . \mathrm{Pp} .35-54$.

MARTÍN GAMERO, Antonio (1862). Historia de la ciudad de Toledo: sus claros varones y monumentos. Toledo: José de Cea.

MASDEU, José Francisco (1795). Historia crítica de España, y de la cultura española en todo género. Madrid: Impresor Antonio Sancha.

MORA RODRÍGUEZ, Gloria (2006). "Coleccionistas españoles en Italia a comienzos del siglo XIX. El monetario de Dámaso Puertas, Médico del XIV Duque de Alba”, en BELTRÁN FORTES, José [et at] (Edit.): Arqueología, Coleccionismo y Antigüedad: España e Italia en el siglo XIX. Sevilla: Universidad, pp. 435 - 457.

ORTIZ ROMERO, Pablo (2013): La quimera del libro: la Comisión de Monumentos de Badajoz y el patrimonio bibliográfico. Badajoz.

- (2012). “José de Viú. De la epigrafía a la restauración del país extremeño” en IÑESTA MENA, Francisco y MATEOS ASCACÍBAR, Francisco José (Coords): España: nación y Constitución y otros estudios sobre Extremadura. Llerena: Sociedad Extremeña de Historia, pp. 305 - 320.

- (2007). Institucionalización y crisis de la Arqueología en Extremadura. Comisión de Monumentos de Badajoz. Subcomisión de Monumentos de Mérida (1844 - 1971). Mérida: Consejería de Cultura.

- (1986). Introducción a una historia de la arqueología en Extremadura. Cáceres: Universidad de Extremadura.

PEREZ BAYER, Francisco (1772). Del alfabeto y lengua de los fenicios y sus colonias. Madrid.

RISCO, Manuel (1791). España Sagrada. Tomo XX. Madrid: Impresión Viuda e hijos de Marín.

RUANO, Francisco (1761). Historia General de Córdoba. Córdoba: Francisco Villalón.

SOLER Y ARQUÉS, Carlos (1861). Huesca Monumental: ojeada sobre su historia gloriosa y apuntes biográficos de sus santos y personajes célebres. Huesca: Jacobo María Pérez.

SALMERÓN, Pascual (1784). Disertación numismática, laberíntica, sobre el descubrimiento de un laberinto en una medalla antigua de Carteia, Capital de Olcadia. Valencia: Impresor Salvador Fauil.

- (1777). La Antigua Carteia o Carcesa, hoy Cieza. Valencia: Impresor Joaquín Ibarra. 
VALCÁRCEL PÍO DE SABOYA Y SPINOLA, Antonio (1773). Medallas de las colonias, municipios y pueblos antiguos de España. Valencia: Impresor Thomas de Orga.

VELÁZQUEZ DE VELAZCO, Luis José (1752). Ensayo sobre los alfabetos de las letras desconocidas que se encuentran en las más antiguas medallas y monumentos. Madrid: Impresor Antonio Sanz.

VIÚ, José (1852). Estremadura. Colección de sus inscripciones y monumentos seguida de reflexiones importantes. Madrid: Impresor Pedro Montero.

VIÚ, José (1846). Colección de inscripciones y antigüedades de Estremadura. Cáceres: Canela y Compañía.

- (1842). Aventuras de una peseta. Madrid: Impresor Sanchiz. 